\title{
Design and Analysis of Emergency Deployable Bridge
}

\author{
Choy Hau Yan and Tan Aik Aik \\ Faculty of Engineering and Technology, Tunku Abdul Rahman University College, Kuala Lumpur, Malaysia \\ Email: choyhy@tarc.edu.my
}

\begin{abstract}
Natural disasters such as flood, earthquakes and volcanic eruptions have always been a serious issue that threatens human lives and caused massive structural damage. Structures such as bridges that links between two areas being destroyed, disaster rescue operations will become more difficult and delayed. This situation leads to research and development of emergency deployable bridges in terms of its effectiveness in disaster rescue operations while optimizing the overall strength and ratio of weight-toloading capacity. This paper focuses on redesigning an emergency deployable bridge with stress analysis and thermal analysis. The modeling design of emergency deployable bridge tested by using $4 \times 4$ vehicle by using SolidWorks. By using Kutzbach equation, its help the design to meet the targeted degree of freedom. There is five major part like deck, pin, cross shaft and deck shaft involve in the structure and A36 structural steel being used in the simulation. Simulation results show $7.75 \%$ decrease on maximum von misses stress and $8.50 \%$ improvement on the Factor of Safety.
\end{abstract}

Index Terms - emergency deployable bridge, scissor structure, simulation

\section{INTRODUCTION}

During unwanted catastrophic events, most of the core structural components found in human civilization, for example, bridges will be destroyed and caused lost connectivity to the isolated region. Therefore, a replacement for the demolished bridges, such as emergency deployable bridges is required.

\section{A. Problem Statement}

Several existing emergency bridge designs are being employed in rescue operations for natural disasters. based on a report, it stated that without a bridge to connect two separated regions, $80 \%$ of the water gaps in the world are unable to be crossed and this is an obstacle for the rescue operatives [1]. One of the devastating disasters that occurred in the Indian Ocean earthquake and tsunami in 2004. The total casualties were more than 200000 people and structural damage was around $\$ 15$ billion. Structures such as bridges were demolished, for example, in Banda Aceh, Indonesia [2].

Therefore, emergency bridge as a replacement for the collapsed bridges will help the disaster relief team. An emergency bridge must be able to be put into action

Manuscript received December 1, 2019; revised August 21, 2020 rapidly and have the ability to cover most of the water gaps. Thus, the emergency bridge design must be optimized based on two main factors: deployment time and coverage span. There are very important that bridge design must be portable and the weight-to-loading capacity ratio also being considered.

\section{B. Research Scope}

To achieve the research requirements of the emergency bridge, the model of the emergency deployable bridge will be designed by using SolidWorks and the model of the emergency bridge as shown in Fig. 1 [3]. The stress check on the structural members must be carried out by FEM analysis. However, there are urgent needs to design a light, strong structural form with no unnecessary material to ensure a bridge that can withstand a heavy load [4]. This project will present the analysis result of the effects of loading and temperature on the bridge and optimization design an emergency deployable bridge on a ratio of weight-to-loading capacity. The model will be tested on the effect of loading and thermal through SolidWorks. For the loading test, the weight of two $4 \times 4$ pick-up truck is applied throughout the bridge span.

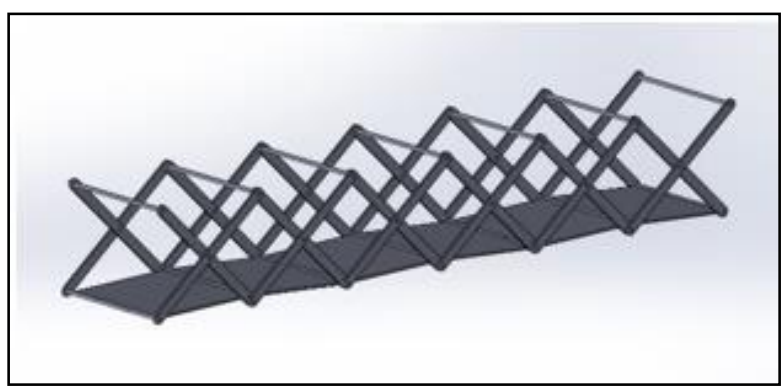

Figure 1. The collapsible scissor bridge

\section{Research Contribution}

Significant destruction to structures such as bridges caused by natural disasters can be observed through past disaster events and consequences of the damage will affect the rescue operations. The lack of access by bridge caused the relief efforts taking alternatives such as water and air transportations to reach the disaster zone. These alternatives including boats and helicopters have limited passenger capacity and several round trips will be required to evacuate the victims from the disaster zone [5]. With the advancement in post-disaster rescue equipment like an emergency deployable bridge, linkage 
to the disaster area can be reconnected and this will benefit the rescue operations, saving more life after a disaster strike. Under a particular loading condition, verification on bridge with stresses could be predicted with analytical models [6]

\section{LITERATURE REVIEW}

The current solution for replacing a collapsed bridge during a natural disaster is a military bridge system. Military bridge system is a temporary bridge that either can be deployed mechanically or be assembled by the human workforce.

\section{A. Military Bridge}

The military bridge can be divided into categories such as assault bridges and tactical bridges. Assault bridges are commonly used for rapid gap crossing for the leading troops to the front line and it typically spans up to $25 \mathrm{~m}$. For longer gap crossing, tactical bridges are used to replace Assault Bridge. One of the examples of Assault Bridge is the Wolverine Heavy Assault Bridge (HAB). The Wolverine is an armored vehicle designed to carry, install and retrieve an assault bridge that has a load capacity of 70 tons. It is capable of providing a connection for the gap of $24 \mathrm{~m}$ long. It requires two operators to operate the system. The crew can deploy the bridge while under armor protection in five minutes from one end of the gap and can retrieve it in ten minutes from both ends [7].

The Medium Girder Bridge (MGB) is an example of a tactical bridge. MGB is a two-girder deck bridge that is lightweight and is used in the forward battle area and communication area. The MGB consists of parts that are produced from a specially developed zinc, magnesium, and aluminum alloy and since it is lightweight, it can be carried without using heavy equipment. It is set-up using workforce such as soldiers and the set-up time is longer than the HAB. The bridge can be supported on unprepared and uneven ground without foundation works.

\section{B. Open Grid Deck Model}

The general term of deployable structures is often applied to a wide range of structural bodies that can be transformed from a closed, compact or retracted configuration to a predetermined deployed or expanded form, where the structures are stable and can carry the load [8]. Open deck bridge designs have the timber sleeper/transoms directly supported by the bridge girders. Due to the lower dead loads of these bridges, they are one of the most popular railway bridges, and their maintenance cost is lower than the ballasted deck bridges. [9]

Significant reductions in dead load can be obtained by removing an existing concrete deck and replacing it with a lighter weight deck. In some cases, further reduction in dead load can be obtained by replacing the existing guardrail system with a lighter weight guardrail [10]. The concept of strengthening by dead-load reduction has been used primarily on steel structures, however, this technique could also be used on bridges constructed of other materials. After an existing deck has been removed, structural members can readily be strengthened, added, or replaced. Several types of lightweight decks are available, including an open steel grid. Open steel grid deck is a lightweight deck system which consists of fabricated, steel-grid panels that are field welded or bolted to the bridge superstructure. Open-grid steel decks are lightweight, typically weighing 15 to $25 \mathrm{lb} / \mathrm{sq} \mathrm{ft}$ for spans up to $5 \mathrm{ft}$.

\section{Temperature Consideration}

Based on the Environmental Engineering Considerations and Laboratory Tests, code-named MILSTD-810, which is a Military Standard designed by the United States, that focuses on the equipment environmental design and test limits to the condition that will be experienced by the equipment during its service life and also provide guidelines to replicate the environmental effects on the equipment in a test chamber. Within the MIL-STD-810G, the low-temperature test, code-named Method 502.5, is one of the tests to be applied to the emergency deployable bridge in this research.

Similar to the low-temperature test mentioned in the previous section, the high-temperature test is also one of the tests found in the Environmental Engineering Considerations and Laboratory Tests. With the code name Method 501.5, the purpose of this test is to replicate high temperature conditions for equipment testing to obtain the data to evaluate the impact of hightemperature environment on the material safety, integrity and performance. One of the shortcomings of this method is it is not practical for evaluating the effects of timedependent performance deterioration that occur due to long term exposure to high temperature. [11]

\section{CONCEPT AND THEORY}

During the design process, one of the important criteria to be evaluated is the factor of safety (FoS). Factor of safety is defined as the ratio of the maximum strength of an object to the load applied on the object where the formula of factor of safety is given as FOS=Maximum strength / Load applied. Incorporating Factor of Safety for a bridge design is crucial as complete testing on the bridge strength is impractical. The Factor of safety is commonly determined by detailed analysis and the FoS for bridges are ranging from 5 to 7 [12].

The extension and retraction of the emergency deployable bridge are designed based on Nuremberg Scissors theory. Nuremberg Scissors, as shown in Fig. 2 is a planar mechanism consisting of several links and pins forming a scissor-like structure which can retract and expand with a given ratio. With this scissors-like linkage, the bridge can be deployed or collapsed with a minimum amount of force. Since Nuremberg Scissors is essentially a collection of rigid bodies linked together by kinematic constraints, the degree of freedom of the system can be determined using Kutzbach equation given by:

$$
F=3(L-1)-2 J-H
$$


Where $\mathrm{F}$ is the degree of freedom, $\mathrm{L}$ is the number of links and $\mathbf{J}$ is the number of lower pair and $\mathrm{H}$ is the number of higher pair. [3]

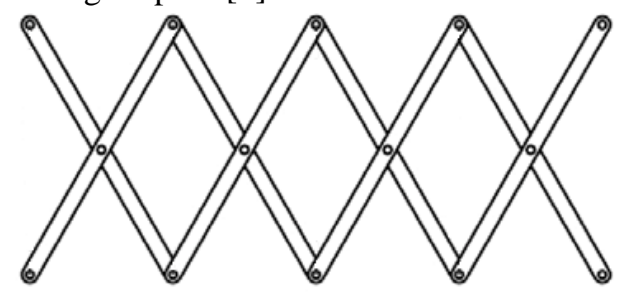

Figure 2. Nuremberg scissors structure

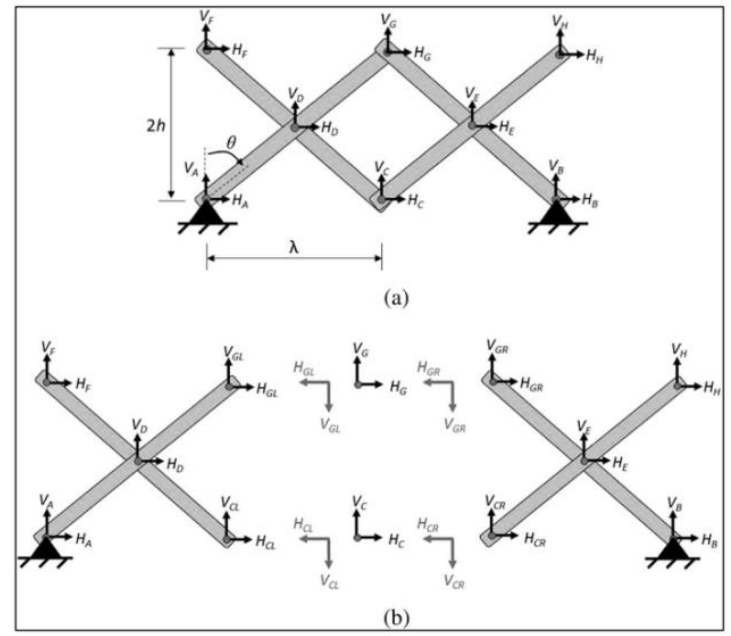

Figure 3. Structural diagram of nuremberg scissors

The scissors model in Fig 3 (a) has the nodal forces acting only on the pivot, hinge and pin support at both sides. Each link has the same length and the same inclination angle $\theta$. The length of the scissor unit is denoted as $\lambda$ and the height as $2 h$. In Fig 3 (b), the left scissor structure has the nodes of $A, C_{L}, D, F$ and $G_{L}$ whereas the right scissor structure has nodes $C_{R}, B, E, H$ and $G_{-} R$. The loading is applied at the nodal locations mentioned and thus no bending moments are transmitted. Therefore, the horizontal $(\mathrm{H})$ and vertical (V) equilibrium equations for the left-hand-side structure are: [13]

$\Sigma^{H}:\left(H_{A}+H_{C L}\right)+\left(H_{F}+H_{C L}\right)+H_{D}=0$

$\Sigma^{V}:\left(V_{A}+V_{C L}\right)+\left(V_{F}+V_{C L}\right)+V_{D}=0$

Also, the moment equilibrium for joints $A, C_{L}, D, F$ and $G_{L}$ are:

$\sum M_{A}: 2 h\left(H_{F}+H_{G L}\right)-\lambda\left(V_{C L}+V_{G L}\right)-{ }_{2}^{2} V_{D}+h_{H_{D}}=0$

$\sum M_{C L}: 2 h\left(H_{F}+H_{G L}\right)+\lambda\left(V_{A}+V_{F}\right)+{ }_{2}^{\lambda} V_{D}+h_{H_{D}}=0$

$\sum M_{F}:-2 h\left(H_{A}+H_{C L}\right)-\lambda\left(V_{C L}+V_{G L}\right)-{ }_{2}^{\lambda} V_{D}+h_{H_{D}}=0$

$$
\sum M_{G L}:-2 h\left(H_{A}+H_{C L}\right)+\lambda\left(V_{A}+V_{F}\right)+\frac{\lambda}{2} V_{D}+h H_{D}=0
$$

The equation 4 to 7 can be linearly combined to become the equations below:

(5) \& (7) and (4)\& (6):

$\zeta\left(H_{A}+H_{C L}\right)+\zeta\left(H_{F}+H_{G L}\right)+\zeta H_{D}=0(\lambda=2 h)$

(5) \& (4) and (7)\& (6):

$\lambda\left(V_{C L}+V_{G L}\right)+\lambda\left(V_{A}+V_{F}\right)+\lambda V_{D}=0$

Besides that, based on the left-hand-side unit formed by member $A\left(G_{L}\right) \&\left(C_{L}\right) F$, the moment equilibrium of each member for pin joint $\mathrm{D}$ can be obtained as follows:

$$
\begin{aligned}
& M(A G L):-\zeta H A+\lambda V A=-\zeta H G L+\lambda V G L \\
& M(C L F): \zeta H F+\lambda V F=-\zeta H C L+\lambda V C L
\end{aligned}
$$

Then, equation $8,9,10$ and 11 were written in matrix form as shown below: -

$$
\begin{gathered}
{\left[\begin{array}{cccc}
1 & 0 & 1 & 0 \\
0 & 1 & 0 & 1 \\
0 & 0 & \zeta & -\lambda \\
-\zeta & -\lambda & 0 & 0
\end{array}\right]\left(\begin{array}{c}
H_{C L} \\
V_{C L} \\
H_{G L} \\
V_{G L}
\end{array}\right)=-\left[\begin{array}{cccc}
1 & 0 & 0 & 0 \\
0 & 1 & 0 & 0 \\
-\zeta & \lambda & 0 & 0 \\
0 & 0 & 0 & 0
\end{array}\right]\left(\begin{array}{c}
H_{A} \\
V_{A} \\
H_{B} \\
V_{B}
\end{array}\right)-\left(\begin{array}{c}
H_{D}+H_{F} \\
V_{D}+V_{F} \\
0 \\
\zeta H_{F}+\lambda V_{F}
\end{array}\right)} \\
\Leftrightarrow\left[R_{1}\right]\left\{C G_{L}\right\}=-\left[Y_{1}\right]\{A B\}-\left\{Z_{D F}\right\} \\
\left\{C G_{L}\right\}=-\left[R_{1}\right]^{-1}\left[Y_{1}\right]\{A B\}-\left[R_{1}\right]^{-1}\left\{Z_{D F}\right\}
\end{gathered}
$$

A similar expression can be written for right-hand-side scissor structure:

$$
\begin{gathered}
{\left[\begin{array}{cccc}
1 & 0 & 1 & 0 \\
0 & 1 & 0 & 1 \\
-\zeta & \lambda & 0 & 0 \\
0 & 0 & \zeta & \lambda
\end{array}\right]\left(\begin{array}{l}
H_{C R} \\
V_{C R} \\
H_{G R} \\
V_{G R}
\end{array}\right)} \\
=-\left[\begin{array}{llll}
0 & 0 & 1 & 0 \\
0 & 0 & 0 & 1 \\
0 & 0 & 0 & 0 \\
0 & 0 & -\zeta & -\lambda
\end{array}\right]\left(\begin{array}{c}
H_{A} \\
V_{A} \\
H_{B} \\
V_{B}
\end{array}\right)-\left(\begin{array}{c}
H_{E}+H_{H} \\
V_{E}+V_{H} \\
\zeta H_{H}-\lambda V_{H} \\
0
\end{array}\right) \\
\Leftrightarrow\left[L_{2}\right]\left\{C G_{R}\right\}=-\left[Y_{2}\right]\{A B\}-\left\{Z_{E H}\right\} \\
\left\{C G_{R}\right\}=-\left[L_{2}\right]^{-1}\left[Y_{2}\right]\{A B\}-\left[L_{2}\right]^{-1}\left\{Z_{E H}\right\}
\end{gathered}
$$

At location $\mathrm{C}$ and $\mathrm{G}$, the forces $V_{C}, H_{C}, V_{G}$ and $H_{G}$ are in the equilibrium with forces $H_{G L}, V_{C R}, H_{C R}, V_{G R}$ and $H_{G R}$.

Therefore, the sum of forces for each scissor unit is:

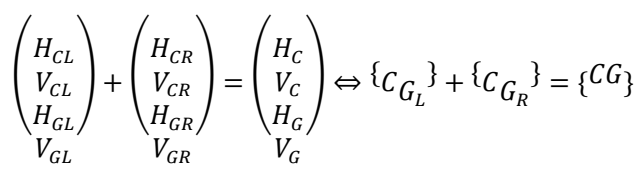

By substituting (12) and (13) into (14) will lead to:

$[P]\{A B\}=\{C G\}+\left[R_{1}\right]^{-1}\left\{Z_{D F}\right\}+\left[L_{2}\right]^{-1}\left\{Z_{E H}\right\}$

where $[P]=\left[-\left[R_{1}\right]^{-1}\left[Y_{1}\right]-\left[L_{2}\right]^{-1}\left[Y_{2}\right]\right]$

Besides that, the emergency deployable bridge should also be able to operate in extremely low-temperature situation of around $-20^{\circ} \mathrm{C}$. This is because there are also some unlikely events such as avalanche that could occur on mountains where the temperature condition is extreme 
compared to the normal application of the emergency bridge [14]. When a matter is subjected to a change in temperature, a change in lengths such as expansion or contraction will take place. Thus, emergency deployable bridge that is being deployed in rescue operations happen in intense cold weathers must be able to withstand the stress due to the change in temperature. The linear expansion of an object subjected to temperature change is given by

$$
\Delta l l o=\alpha \Delta T
$$

where

$\Delta l$ is the change in length.

lo is the original length.

$\alpha$ is the thermal expansion coefficient.

$\Delta T$ is the change in temperature.

\section{RESEARCH METHODOLOGY}

\section{A. Simulation Model Design Parameter}

The deployable bridge is designed to fit in the trunk of a 4 × 4 pick-up truck and therefore the overall outer dimensions of the emergency bridge is $2.2 \mathrm{~m}$ (width), 2 $\mathrm{m}$ (height) and $14 \mathrm{~m}$ (Length). This is the dimensions when the bridge is retracted. The model of the deployable bridge is shown in Fig. 4 whereas Fig. 5 shows the bridge when retracted. [3]

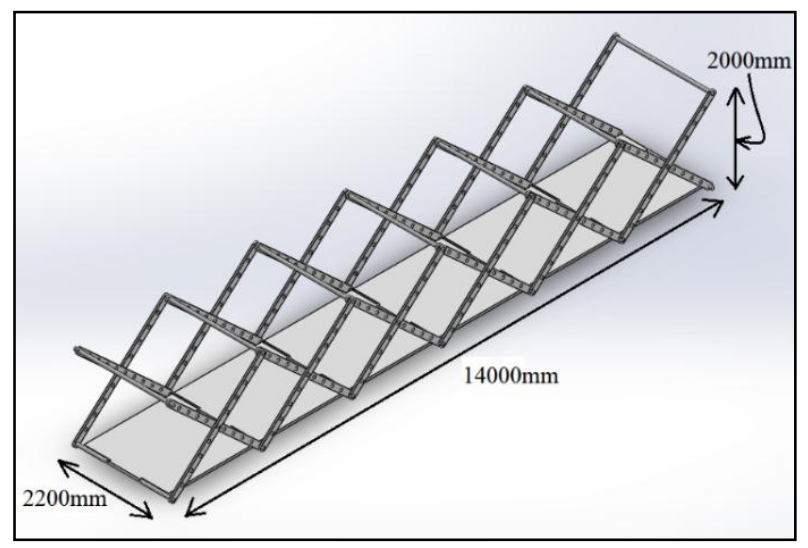

Figure 4. The dimension of deployed emergency bridge

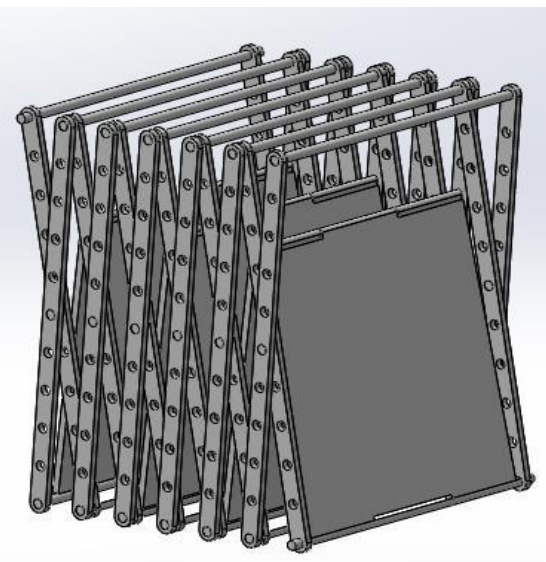

Figure 5. The retracted deployable bridge
The emergency bridge model creation process starts by constructing the model of each component of the bridge such as link, deck, cross shaft, deck shaft. The dimension of each component is shown in Table I.

TABLE I. DIMENSION OF EACH STRUCTURAL COMPONENT

\begin{tabular}{|c|c|}
\hline Component & Dimensions \\
\hline Link & $\begin{array}{c}\text { Length: } 3312 \mathrm{~mm} \\
\text { Width: } 150 \mathrm{~mm} \\
\text { Thickness: } 50 \mathrm{~mm} \\
\text { Hole Diameter: } 80 \mathrm{~mm}\end{array}$ \\
\hline Deck & $\begin{array}{c}\text { Length: } 2340 \mathrm{~mm} \\
\text { Width: } 2200 \mathrm{~mm} \\
\text { Thickness: } 60 \mathrm{~mm}\end{array}$ \\
\hline Cross shaft & $\begin{array}{c}\text { Length: } 2560 \mathrm{~mm} \\
\text { Diameter: } 78 \mathrm{~mm}\end{array}$ \\
& Length: $2560 \mathrm{~mm}$ \\
& Diameter: $78 \mathrm{~mm}$ \\
\hline Deck Shaft & Length flat surface: $2260 \mathrm{~mm}$ \\
& Liameter: $78 \mathrm{~mm}$ \\
& Length: $120 \mathrm{~mm}$ \\
\hline
\end{tabular}

\section{B. Static Loading Simulation Setting}

The material chosen for the simulation was ASTM A36 and based on [15], the mechanical properties of A36 steel was shown in Table II.

TABLE II. PROPERTIES OF A36 STEEL

\begin{tabular}{|c|c|}
\hline Mechanical Properties & Value \\
\hline Elastic Modulus, E & $190 \mathrm{Gpa}$ \\
\hline Poisson Ratio, $v$ & 0.29 \\
\hline Shear Modulus, G & $73 \mathrm{Gpa}$ \\
\hline Ultimate Tensile Strength, UTS & $480 \mathrm{Mpa}$ \\
\hline Yield Strength & $250 \mathrm{Mpa}$ \\
\hline Mass density, $\rho$ & $7900 \mathrm{~kg} / \mathrm{m}^{3}$ \\
\hline
\end{tabular}

The fixture applied in simulation was at both bridge ends and the load applied was the weight of two pickup trucks of $19306.08 \mathrm{~N}$.

\section{Thermal Simulation Setting}

There were two tests conducted for the thermal simulation which were the low-temperature test with a temperature load of $-51^{\circ} \mathrm{C}$ and the high-temperature test with a temperature of $71^{\circ} \mathrm{C}$. Both were based on the temperature test from the Environmental Engineering Considerations and Laboratory Tests. [11] 


\section{Redesign on Emergency Bridge}

Redesign on an emergency bridge by using open grid deck for the bridge as shown in Fig. 6 and Fig. 7. This modification was based on the method of strengthening the existing highway bridge [10]. The thickness of the deck was increased from $60 \mathrm{~mm}$ to $120 \mathrm{~mm}$ without additional material required since there are holes on deck to remove material.

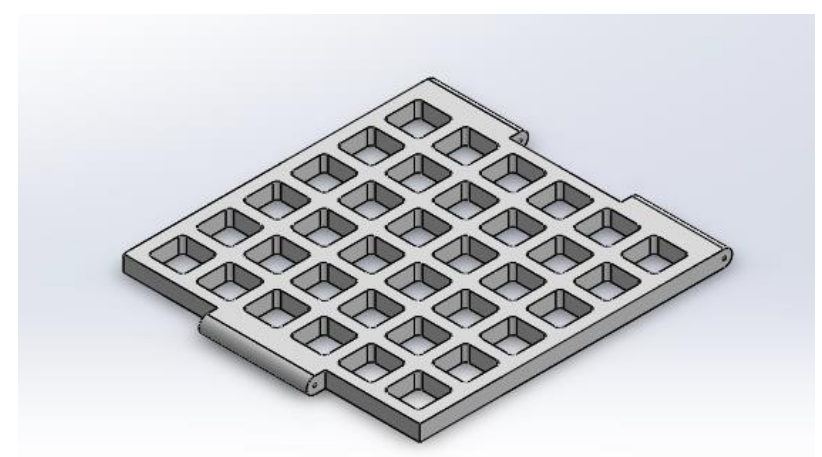

Figure 6. Open grid deck model

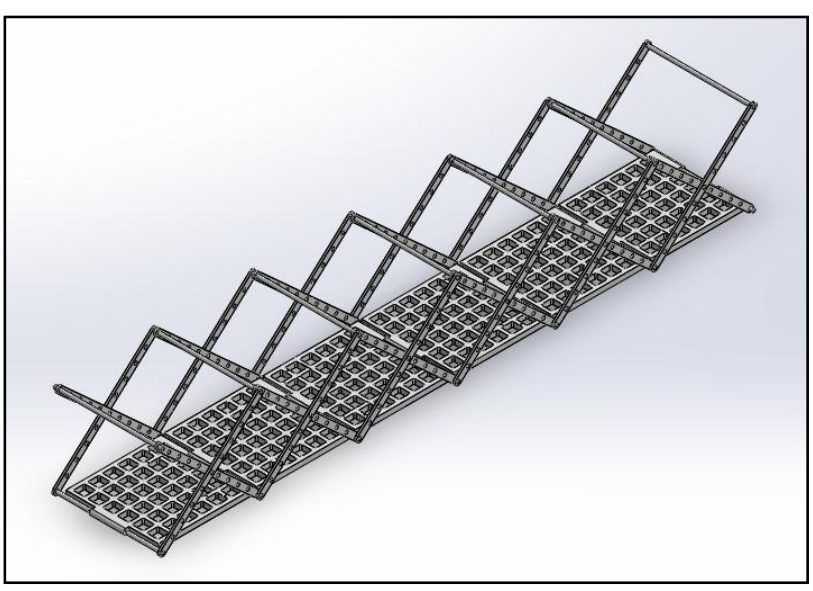

Figure 7. Emergency bridge with open grid deck model

\section{RESULT AND DISCUSSION}

\section{A. Load Simulation on Bridge Design}

For the setting of external load, two loads were applied to the entire bridge model, which were the static loading and the gravitational effect. Based on the setting in [3], the static force applied was the weight of two $4 \times 4$ pickup trucks. The pick-up truck chosen was the Ford Ranger, where the total force applies is $2100070 \mathrm{~N}$ for a total weight of trucks were applied on the emergency bridge. The Ford Ranger has a dimension such as a wheelbase of $3.226 \mathrm{~m}$, length of $5.359 \mathrm{~m}$, width of $1.849 \mathrm{~m}$ and height of $1.815 \mathrm{~m}$. The location of the static force applied was based on the wheelbase of the pick-up truck. The gravitational effect of $-9.81 \mathrm{~m} / \mathrm{s} 2$ was also included in where it is normal to the bridge deck. Table III show simulation results and Fig. VIII show stress simulation results on bridge model.
TABLE III. StATIC LOADING SimULATION RESUlt [4]

\begin{tabular}{|l|l|}
\hline Type & Max \\
\hline von Mises Stress & $1.603 \times 10^{8} \mathrm{~N} / \mathrm{m}^{2}$ \\
\hline Displacement & $5.812 \mathrm{~mm}$ \\
\hline Factor of Safety & 1.558 \\
\hline
\end{tabular}

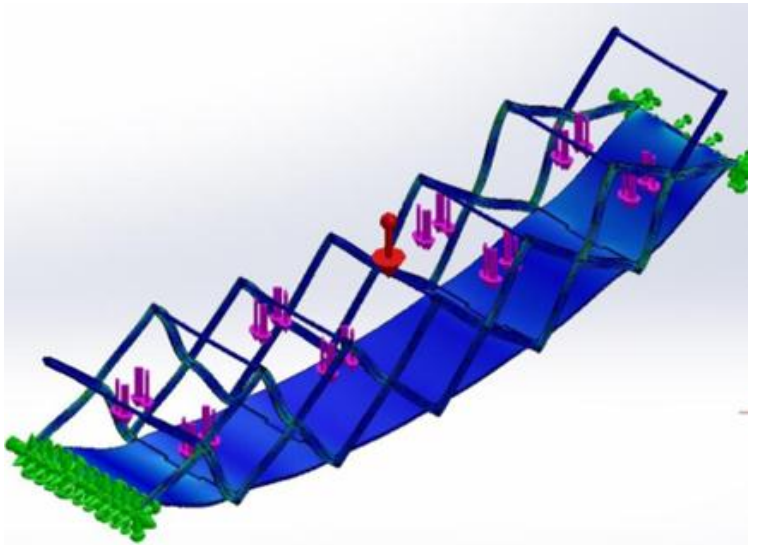

Figure 8. Load simulation on bridge model

By referring to the simulation results from [3], its shows that simulation on emergency bridge design are maximum von Mises Stress of 149.48Mpa, the maximum displacement of $15.741 \mathrm{~mm}$ and a Factor of Safety of 1.67. By comparing the results obtained from table III, where maximum von Mises are Stress of 160.30Mpa and FoS of 1.56, the percentage of difference for both results are less than $20 \%$. The different value of simulation results because the author applies load on the entire bridge deck but my load applies on surface contact between wheels and the deck bridge. Therefore, simulation results can be said as validated.

\section{B. Load Simulation on One Grid Deck Bridge Design}

By apply the same simulation setting on an emergency bridge setting with open grid decks, Table IV shows good results and simulation results shown in Fig. 9. By comparing the results from Table IX with research in [3], it was observed that the performance of the modified design is better than the original design. The Factor of Safety has increased by $8.50 \%$ and maximum von misses stress increase by $7.75 \%$. Thus, the emergency bridge becomes safer as it can handle unexpected. Next, the maximum displacement for the original bridge design was greater than the modified bridge design and this shows that the modified bridge design is stiffer. Moreover, since the open grid decks bridge was designed to have the same weight as the original design, the modified bridge with higher FoS have better weight-toloading capacity ratio.

TABLE IV. LOAD SIMULATION RESULT ON ONE GRID DECK BRIDGE DESIGN

\begin{tabular}{|l|l|}
\hline Type & Max \\
\hline von Mises Stress & $1.379 \times 10^{8} \mathrm{~N} / \mathrm{m}^{2}$ \\
\hline Displacement & $4.396 \mathrm{~mm}$ \\
\hline Factor of Safety & 1.812 \\
\hline
\end{tabular}




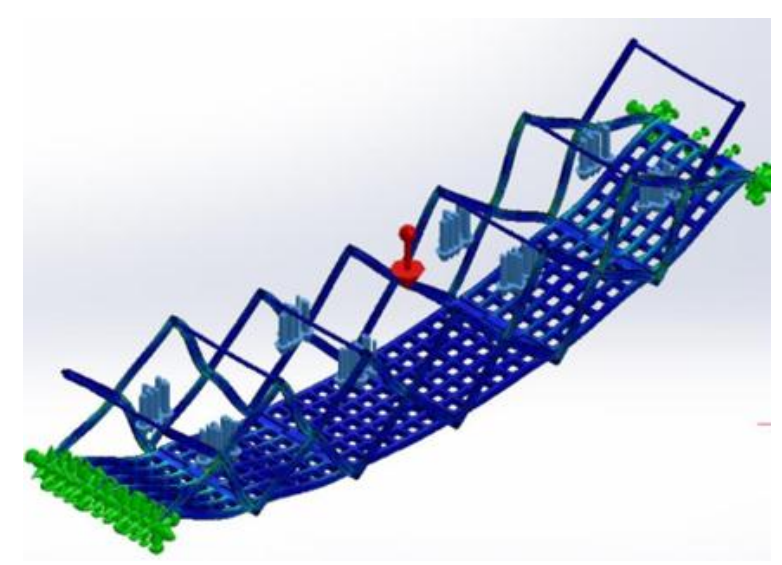

Figure 9. Load simulation on open grid deck bridge.

\section{Thermal Simulation on Bridge Design}

The purpose of the thermal simulation is to assess the performance of the emergency bridges if it were placed in a cold or hot weather environment. Firstly, the lowtemperature test (Method 502.5) under the MIL-STD-810 applies temperature of $-51{ }^{\circ} \mathrm{C}$ to the bridge as it was assumed that the bridge will be used worldwide whereas the high-temperature test (Method 501.5), applies temperature of $71^{\circ} \mathrm{C}$ to the bridge. Based on Table $\mathrm{V}$ and Table VI, the maximum displacement for the modified bridge design for both low and high-temperature tests were lower than the original bridge design. This is due to the higher thickness of the bridge deck and thus making the bridge more rigid.

TABLE V. Thermal SimUlation Result ON BRIDGE Model

\begin{tabular}{|l|l|}
\hline Type & Max Displacement \\
\hline Low temperature $\left(-51^{\circ} \mathrm{C}\right)$ & $9.088 \mathrm{~mm}$ \\
\hline High temperature $\left(71^{\circ} \mathrm{C}\right)$ & $4.397 \mathrm{~mm}$ \\
\hline
\end{tabular}

TABLE VI. Thermal Simulation Result On OPEn DeCK BRIDGE.

\begin{tabular}{|l|l|}
\hline Type & Max Displacement \\
\hline Low temperature $\left(-51^{\circ} \mathrm{C}\right)$ & $7.887 \mathrm{~mm}$ \\
\hline High temperature $\left(71^{\circ} \mathrm{C}\right)$ & 3.291 \\
\hline
\end{tabular}

\section{CONCLUSION}

This research has presented the numerical analysis of the emergency deployable bridge that utilizes the concept of scissor-like structure. Design and modification proposed of the emergency deployable bridge are based on the literature review and cited studies from research papers with solid analysis result. With the open grid deck bridge design, the overall strength and the ratio of the weight-to-loading capacity of the emergency bridge were able to be improved when compared to the initial bridge design. Thus, the objectives of the research are achieved.

One of the limitations of the emergency bridge design onto the bridge is the overall weight of the bridge. Without sacrificing the strength of the emergency bridge, an emergency deployable bridge should be as lightweight as possible for easy transporting and effective deployment during the occurrence of the natural disaster. Thus, future works on studying and analyzing method on the bridge weight reduction without compromising the overall strength of the bridge should be conducted. One of the examples of lightweight material that could replace the current material selection is the Fiber Reinforced Polymer (FRP) as the material has a high strength to weight ratio.

\section{CONFLICT OF INTEREST}

The authors declare no conflict of interest.

\section{AUTHOR CONTRIBUTIONS}

Mr Choy Hau Yan identified and discover the problem on the deployable bridge. Mr Tan Aik Aik contribution in literature review and simulation results.

\section{ACKNOWLEDGMENT}

This research was supported by Tunku Abdul Rahman University College. We are thankful to the staff of the department of mechanical engineering who provide expertise that greatly assisted the research.

\section{REFERENCES}

[1] P. Bischmann, "River crossing in the central region," NATO's Sixteen Nations, no. 3, pp. 76, 1985.

[2] C. McCall, "Remembering the Indian ocean tsunami," Elsevier Ltd, New York. 2014.

[3] M. Biro and N. Bakar, "Design and analysis of collapsible scissor bridge," EDP Sciences, vol. 152, pp. 3-5. 2018.

[4] A. Ichiro and N. Masatoshi, "Development of a prototype deployable bridge based on origami skill," Automation in Construction, no. 32, pp. 104-111, 2013.

[5] C. Murty et al, "Response and recovery in India after the December 2004 great Sumatra earthquake and Indian ocean tsunami," Earthquake Spectra, June 22, pp. 731-758, 2006.

[6] G. Lederman and Z. You, "A novel deployable tied arch bridge," Engineering Structures, vol. 70, pp. 1-10, 2014.

[7] H. Greene, "The grizzly and the wolverine," Engineer Bulletin, Issue August. 1996.

[8] A. Grosso and P. Basso, "Deployable structures," Advances in Science and Technology, vol. 83, no. 9, pp. 122-131. 2013.

[9] C. Ali, "Assessment and maintenance of open deck railway bridges," 9h Australian Small Bridges Conference, 2019.

[10] F. Klaiber, K. Dunker, and T. Wipf, "Methods of strengtheniguang existing highway bridges, transportation resesarch board," Washington, D.C. 1987.

[11] D. Do, "Environmental engineering considerations and laboratory tests," Department of Defense, Arlington County, 2000.

[12] F. Beer and R. Johnson, Mechanics of Materials, 2nd ed., McGraw-Hill, New York. 1992

[13] Y. Chikahiro, et al., "Experimental and numerical study of fullscale scissor type bridge," Automation in Construction, no. 71, pp. 171-180. 2016.

[14] G. Sedlacek, H. Trumpf, and U. Castrischer, "Development of a light-weight emergency bridge," Structural Engineering International, no. March, pp. 282-287. 2004.

[15] AISC, "Steel construction manual," 8th ed., American Institute of Steel Construction, Berkeley. 2005

Copyright (C) 2020 by the authors. This is an open access article distributed under the Creative Commons Attribution License (CC BYNC-ND 4.0), which permits use, distribution and reproduction in any medium, provided that the article is properly cited, the use is noncommercial and no modifications or adaptations are made. 
Mr Choy Hau Yan was born at Kedah, Malaysia on 17 January 1978. He obtained his master's degree in Mechanical Engineering at National University of Malaysia, Malaysia in the year of 2002. His major research interest is in the field of finite element analysis, CFD simulation and engineering design.

He had extensive working experience as a lecturer at Tunku Abdul Rahman University College, Malaysia for 15 years. He has previous publication regarding finite element analysis.

Mr. Choy is currently the members of Board of Engineer of Malaysia (BEM), a qualified Certified SolidWorks Professional and a member of Technologist Professional

Mr Tan Aik Aik has just completed his Bachelor Degree in Mechanical Engineering at Tunku Abdul Rahman University College, Malaysia in the year of Tan Aik Aik. He partially contributed in this research under the supervision of Mr Choy Hau Yan. 